
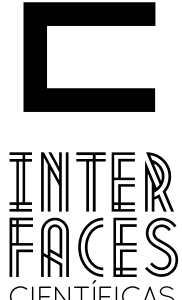

CIENTÍFICAS

HUMANASE SOCIAIS

ISSN IMPRESSO 2316-333X

ISSN ELETRÔNICO 2316-3828

\title{
REPRESENTAÇÃO FEMININA, IDENTIDADE MASCULINA
}

Djalma Thürler ${ }^{1}$

\section{RESUMO}

Neste artigo, buscamos analisar o episódio controverso envolvendo a top model brasileira Gisele Bündchen e a marca de lingerie Hope. Numa polêmica campanha, a marca leva para a televisão um discurso de "sensualidade" feminina que supera a "racionalidade" masculina, ofendendo um sem-número de mulheres no país na medida em que reproduz um discurso sexista. No entanto, buscamos fazer uma leitura a partir de um viés invisibilizado, a saber, um ideal de masculinidade que tem como personagem hegemônico um homem (heteros)sexualizado, provedor e protetor. As duas imagens de gênero implicam em desigualdades que, desde o último século, têm sido combatidas e comprometem a busca por um equilíbrio sócio-cultural entre as posições femininas e masculinas.

\section{PALAVRAS-CHAVE}

Hope (marca). Gênero. Normatividade. Masculinidades.
Rafael Aragão ${ }^{2}$

\section{ABSTRACT}

In the following paper we intend to analyze the controversy involving the top model Gisele Bündchen and the brand of lingerie called Hope. In a polemic advertisement, the brand spreads, through television, a speech of a sensual woman who overcomes a masculine "rationality", insulting a number of Brazilian women, since it reproduces a sexist speech. Nevertheless, we aim to make an analysis through an invisible bias, that is, an ideal of masculinity that has an (heteros)sexualized man as a hegemonic character, who is both provider and protector. Both images of gender presuppose inequalities that, since last century, have been fought and compromise the pursuing of a socio-cultural balance between feminine and masculine positions.

\section{KEYWORDS}

Hope (brand). Gender. Normativity. Masculinities. 


\section{RESUMEN}

En este artículo, se analiza el episodio polémico con la participación de la top model brasileña Gisele Bundchen y la marca de lencería HOPE. En una polémica campaña, la marca trae a la televisión un discurso de la "sensualidad" femenina que supera la "racionalidad" masculina, ofendiendo a un sinnúmero de mujeres en el país, ya que juega un discurso sexista. Sin embargo, hacemos una lectura de un sesgo de hechos invisibles, es decir, un ideal de masculinidad que tiene como personaje hegemónico un hombre (hete- rosexual) proveedor y protector. Las dos imágenes implicam en desigualdades que desde el siglo pasado se combaten y comprometen la búsqueda de un equilibrio entre las posiciones socio-culturales masculinas y femeninas.

\section{PALABRAS CLAVE}

Hope (marca). Género. Normatividad. Masculinidades.

\section{PRIMEIRAS IDEIAS}

Hoje, se Gisele Bündchen estrela uma campanha publicitária, é certo que o produto vai chamar atenção. Para o bem e para o mal. Foi o que aconteceu com a última campanha de lingerie da marca Hope no mercado brasileiro. Isso porque nos vídeos a top model ensina a mulher brasileira a manipular o seu companheiro com seu charme feminino. Assinada pela agência Giovanni+Draftfcb, a campanha é clara: "Você é brasileira. Use o seu charme".

Na primeira oportunidade em que vimos os vídeos, pareceu-nos revisitar uma polêmica já cara à moda, a de que os corpos magros das modelos inspiram as mulheres de modo enviesado. Isso aliado às imagens da divulgação - marcando o "errado" como o corpo feminino escondido e o "certo" aquele sinuoso que "pode" usar determinado tipo de lingerie (Figura 1) - gera um impacto sobre como discutimos a normatização dos corpos e as influências e os perigos de uma normalidade compulsória. No entanto, esse problema não foi central na condenação da campanha.

Os ensinamentos de Bündchen apontavam que o fato e o argumento pouco importam na hora de convencer um homem; a estratégia feminina é sempre

certeira se usa do corpo e da sedução. Nos três vídeos da campanha, a modelo quer compartilhar uma notícia "bem feminina”, mas, para evitar uma reação "propriamente masculina”, o faz apenas usando lingerie. Infalível mesmo é apostar que ele não se segura dentro das calças.

Pois bem, aparentemente o corolário ofendeu inúmeras brasileiras, sobretudo por emoldurar uma mulher-objeto-sexual, "vítima" do seu corpo como instrumento nas relações de gênero. Além disso, uma campanha que reforça, em três vídeos, uma sub-capacidade ("Amor, eu bati o seu carro. De novo"), futilidade ("Amor, eu estourei o limite do cartão de crédito. Do seu e do meu") e carência (“Amor, mamãe vem morar com a gente") femininas atinge não apenas a vaidade das mulheres, como "ignora" a nova ordem social nas relações entre elas e os homens.

Mas o problema aqui vai além de uma guerra dos sexos que busca reproduzir um lugar subalterno à mulher - embora certamente essa tenha sido a razão central das críticas aos vídeos e sua consequente proibição. 0 que está no centro desta disputa é um panorama de gêneros duros e reacionários em que a 
mulher ainda precisa se justificar para o homem - e ele, por sua vez, se afirma quase exclusivamente em relação à sua libido heterossexual. Nesse sentido, importa considerar que a produção da campanha opera conhecimentos coletivos em disputa, a saber: o corpo belo, a mulher sedutora e o macho alfa.

A Gisele de lingerie na passarela e a Gisele de lingerie na propaganda são dois problemas bastante diferentes. No mundo da moda, é permitido e demandado que os corpos sejam aqueles bem preparados fisicamente e se encaixem em uma métrica da beleza industrial - que, por sua vez, é o ideal de beleza que transita hegemonicamente em nosso cotidiano. $\mathrm{Na}$ TV, no entanto, em que estão circulando tipos indivi- duais (sutilmente) mais diversos, esse tipo de normalização é uma violência aos corpos que, efetivamente, não têm meios de atingir o ideal industrial.

Nesse caso, o que separa a Gisele do desfile e a Gisele da propaganda é o fato de que, a despeito de toda a violência simbólica emanada do modelo da moda para a realidade social, ele é permitido, apagado, como se a métrica da beleza se justificasse em espaços distintos. Além disso, no caso da TV, encontramos muito clara - quase materialmente - o juízo de valor do certo e do errado, posterizado nos quadros do vídeo. 0 certo/errado da passarela existe difusamento enquanto a campanha o escancara com uma assinatura (Figura 1).

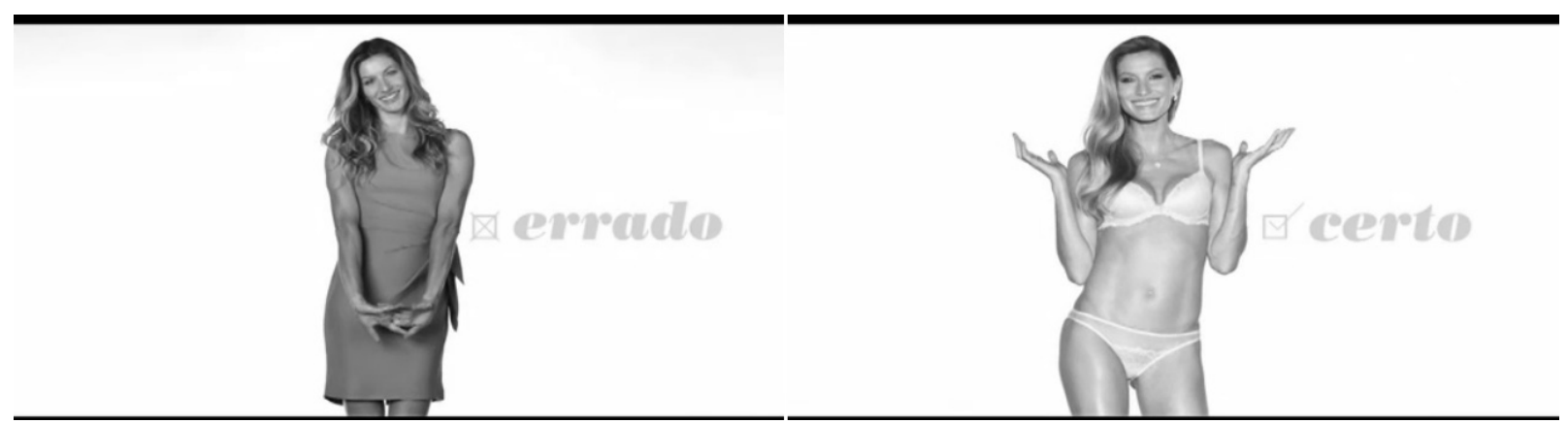

Figura 1: As noções de 'certo' e 'errado' a partir da campanha da Hope.

Se concordamos que o belo é um juízo histórico, com efeito, não podemos insistir em 'certo' ou 'errado' desvinculado da lei que institui o valor estético e político da beleza. Nesse sentido, o próprio belo está assentado em relações disciplinares. Embora este lado da polêmica esteja mais apagado, não é exclusivamente a estratégia justificativa que a propaganda chama de certa, mas também o corpo que pode usar tal estratégia é "certo".

É importante observar que os nossos produtos culturais falam de um repertório construído e comum no seio social e, embora o lugar da mulher hoje seja qualitativamente outro, ainda persistem visões em que o valor da figura feminina é concebido em estrutura de diferença binária. Falando especificamente em publicidade, apesar das regulações, a mulher da propaganda ainda desperta o repertório que tende para um sexo frágil, um corpo sensualizado, uma beleza industrial - como da mesma forma os corpos masculinos são retos e musculares, sensualizados a partir de uma visão hegemônica da posição de dois gêneros.

No que diz respeito à posição em que a figura feminina é colocada, podemos sim dizer que a campanha é machista. Mas deve ser alertado que esta campanha não é mais ou menos machista que outras. Por exemplo, os "pôneis malditos" que ficaram populares na internet fazem parte de um saber deste tipo. Por que um homem deve ser proprietário de carros mais 
potentes? Em que medida um modelo diferente vai comprometer a sua condição masculina? É necessário ser homem dentro deste modelo? Embora a questão de masculinidade hegemonizada esteja quase a olho nu na campanha, ela foi retirada do ar porque ofende a infância e não porque engessa o exercício de ser homem.

Nesse sentido, não podemos deixar de reconhecer nos intervalos comerciais da TV que a família de margarina ainda está lá, que a mulher dona de casa ainda promove sabão em pó, que as propagandas de cerveja ainda têm mulheres bastante sensualizadas etc. Ocorre que a campanha da Hope atinge de forma mais sensível a fratura do problema.

É importante lembrar que, embora os discursos sexistas se confundam com o próprio conceito de machismo, uma ação sexista, com efeito, é aquela que privilegia determinado gênero em detrimento dos outros - e esse privilégio deve ser lido também por seu caráter estereotípico. Giselle de lingerie operando um argumento sensualizado para convencer o parceiro é um discurso sexista tanto porque a figura feminina enquadrada no vídeo de certo modo reporta um mito do feminino incapaz ou problemático quanto porque interdiz o projeto de um homem exclusivamente sexualizado, que é de modo opaco uma violência contra os homens que não se reconhecem ali e ao mesmo tempo representa a pressão social para que a masculinidade seja concebida como este modelo.

Em toda a polêmica da campanha, este é um viés ignorado: o da construção social da masculinidade. Em nenhum momento é questionada a posição de um homem que responde exclusivamente ao apelo sensual/sexual da mulher, como se essa fosse a única e legítima projeção de um exercício masculino. De modo geral, na publicidade, para toda mulher que é bonita, sensual e dócil existe um homem que é potente, se interessa por cerveja, futebol e sexo. Ele também é dócil. É um homem acrítico de sua própria condição masculina - porque apenas responde a um projeto de reconhecimento social de sua masculinidade - que será convencido pela lingerie.

\section{MULHERES DÓCEIS, HOMENS DÓCEIS}

Para que a masculinidade esteja apagada como problema no seio das nossas dinâmicas sociais, colaboram os séculos de uma sociedade ocidental legislada a partir de espaços decisórios masculinos e os questionamentos nascidos com a chamada revolução sexual em que minorias de gênero questionam o patriarcado.

Com os movimentos feminista, lésbico e gay a partir da década de 1960, o papel e lugar do homem heterossexual passa a estar inserido numa série de disputas sociais que têm no desequilíbrio das relações de gênero sua bandeira fundamental. A divisão do trabalho, os direitos civis, o (des)arranjo familiar, enfim, os temas que perpassam o relacionamento entre gêneros mudam e não se pode esperar que o conhecimento da masculinidade e seu exercício cotidiano passem incólumes por estas mudanças, que, mesmo quando não totalmente respeitadas, semeiam a transformação nas relações entre estes sujeitos e entre eles e as instituições sociais.

Mas o reconhecimento da masculinidade como um projeto social de exercício de poder antecede este contexto. Pedro Paulo Oliveira (2004) consegue nos mostrar um panorama histórico desde a Idade Média em que os exercícios masculinos se delineiam para acentuar um projeto de proteção, provisão e potência. 
0 lar, a religião, o esporte, as forças armadas, a arte etc. são espaços em que os discursos centrados numa moral masculina reproduzem esta relação de poder. Podemos, inclusive, encontrar a construção de uma masculinidade clássica que também é fundamentada na honra, no corpo, no exercício público, que se arrasta até os nossos dias como retrato ideal.

A masculinidade é construída como moral e política feita para e por homens e, por esta razão, os corpos masculinos precisaram ser comportalmente docilizados e disciplinados. Queremos dizer com isso que a masculinidade é um conhecimento histórico interessado, que faz uso do poder institucional por meio da figura masculina. Evitamos politicamente a ideia de que os homens, por direito, devam operar os espaços de decisão social por dois motivos: porque isso significa que os corpos masculinos estão colonizados pelo interesse hegemônico e acabam por realizar opressões contra outros sujeitos sociais fora do domínio da hegemonia - em especial às mulheres, mas também aos outros homens e, enfim, a eles mesmos; segundo, porque em uma realidade socialmente solidária, todos os gêneros podem falar por si, encontrar formas de desestabilizar a normalidade compulsória e trabalhar em uma dinâmica mais equilibrada, afastada da metáfora da guerra de sexos.

O que existe na campanha “Hope Ensina”, portanto, é uma forma de docilidade dos corpos dos homens: uma biografia masculina que se afirma quase exclusivamente em sua relação com a (heteros)sexualidade, mas também porque esse homem protege e provê sua companheira.

Importa apontar que o discurso da heterossexualidade é apagado em nosso convívio social por meio do discurso do essencialismo biológico. Porém, mais que isso, uma biografia eminentemente heterossexualizada opera a colonização do masculino na medida em que requer que o homem seja aparente e permanentemente responsivo ao desejo pelo sexo diferente, além de interessado, também de modo permanente, pelo sexo, pelo conhecimento do sexo e possa desempenhar estas demandas a contento.

No entanto, o conceito de heterossexualidade começa a ser utilizado apenas no final do século XIX (KATZ, 1996). 0 investimento em uma sexualidade de sexo diferente e exclusivo é uma construção recente, reforçada, sobretudo, por um discurso clínico que, apropriado pelos meios de comunicação, acabou por se popularizar como uma norma social. Um aspecto importante é o fato de as teorias sobre sexualidade em voga indicarem apenas um desejo sexual, vinculando imediatamente o biológico ao psicológico. "Os sentimentos eram considerados femininos ou masculinos exatamente no mesmo sentido que o pênis ou o clitóris: a anatomia era igual à fisiologia, a fisiologia do sexo determinava o sexo dos sentimentos" (p. 62). Importante perceber que, mesmo considerando a existência de desejo para com o mesmo sexo, a condição final do desejo é polar; quer dizer, o desejo é masculino ou feminino em si mesmo e está ligado ao sexo diferente. Assim, um desejo feminino poderia residir num homem e o mesmo ocorrer com a mulher (ser portadora de um desejo masculino). Esse pensamento é fundador da polaridade homossexualidade/ heterossexualidade.

Como parte de um corpo de imagens que organizam o imaginário social sobre a organização das diferenças de gênero, a masculinidade é uma categoria hostil. Diferente da feminilidade, que é instituída pejorativamente também como domínio do flexível, a masculinidade é uma categoria rígida em seus princípios, não tolerante ao comportamento diferente. A princípio, é evidente a dominação do pensamento masculino e heterossexual em relação às mulheres dominação cuja existência os movimentos sociais têm combatido. Mas é importante perceber que, por meio da mesma violência simbólica, a dominação masculina institui um habitus das relações gênero e impõe sua agenda sobre os indivíduos do sexo masculino.

Nesse sentido, não podemos deixar de observar que, ao mesmo tempo em que uma masculinidade he- 
gemônica outorga status "positivo" a um dado sujeito, ela também requer dele disciplina e policiamento incessantes. Kaufman vai observar neste desdobramento um paradoxo do poder investido nos homens, pois “as formas em que nós homens temos construído nosso poder social e individual são, paradoxamente, fonte de uma forte dose de temor, isolamento e dor para nós mesmos" (1999, p. 2, tradução nossa).

O maior paradoxo da identidade masculina é o fato de que ela é sempre menos uma propriedade do que uma aspiração, jornada que nunca se confirma totalmente, mas também não permite descanso no exercício social. 0 indivíduo é sempre tanto mais homem quanto mais reivindica para si as atribuições do masculino e tem o poder de convencer sobre a conquista de tais e quais atributos. E, ao mesmo tempo, nenhum homem é depositário do poder que enuncia sua própria masculinidade; quando muito, faz parte de uma sociedade que reconhece a masculinidade (do outro), um corpo simbólico que só pode ser concedido e refutado. A masculinidade não apenas produz a atitude masculina, mas “provoca sua própria verificação e faz acontecer o que ela prognostica” (BOURDIEU, 2009, p. 44).

É por meio deste argumento que podemos perceber como "Hope Ensina" não é apenas violenta contra as mulheres, mas também contra os homens. São eles que precisam responder de forma patente ao corpo de Gisele Bündchen. São eles que devem ser convencidos pelo corpo feminino ou pela lingerie, a despeito do próprio problema que se coloca (o carro estragado, o cartão de crédito, a sogra). São eles, sobretudo, que aparecem como personagem-alvo da intenção da campanha, pois parte-se do pressuposto que todos os espectadores farão o mesmo percurso crítico para compreender a propaganda - ou seja, este homem irá perdoar uma Gisele de lingerie.

0 que queremos discutir, portanto, é que a campanha ofende a todos nós que estamos pensando e trabalhando por uma sociedade que quebre a barreira binária de gênero. E esse esforço não pode estar restrito apenas à Academia, ao contrário, precisa ser incorporada em nosso dia-a-dia.

Para nós, pós-estruturalistas, a identidade está situada no campo da diversidade, do movimento, da alteridade e da diferença, em contraposição à ideia de identidade como permanência, embora reconheça que, na sociedade contemporânea, ainda se faça forte o apego à definição das identidades.

Nesse sentido, o que a propaganda tem de ruim e perigoso? É que as práticas sociais cristalizadas e preconceituosas, reproduzidas nas diferentes instituições, são a sinalização e a materialização da concepção que desconsidera a diversidade como característica básica dos indivíduos. Quando se pressupõe que todos têm que ser idênticos uns aos outros, aqueles que não se enquadram na igualdade almejada são situados fora do mundo social. A concepção da identidade permeada pela ideia da igualificação consolida a existência de processos de segregação.

Fausto Rodrigues de Lima, coautor do livro Violência Doméstica - A Intervenção Criminal e Multidisciplinar, assinala em 'A Folha de São Paulo' que a propaganda discrimina os homens, afinal, "como todo projeto de dominação e preconceito, a discriminação de gênero, embora baseada numa suposta inferioridade feminina, atinge a todos, porque cria regras 'naturais' para o comportamento dessa ou daquela pessoa, baseando-se apenas em seu sexo. Adeus, individualidade e diversidade", diz o Promotor de Justiça do Distrito Federal. E mais, "nós, homens do século 21, somos seres pensantes. Não queremos prover ninguém, almejamos unir esforços. Se por acaso nossa renda for insuficiente ou nula, que nos respeitem. Gostamos, sim, de sexo, mas não pensamos nisso 24 horas por dia. Nos interessa o futebol mas também o balé, a música, a arte, a poesia. E choramos, sim".

A fala-desabafo de Fausto Rodrigues de Lima articula e dialoga com as principais correntes de pensamentos masculinistas, as que indagam o padrão 
tradicional de identidade masculina e oferece aos sujeitos masculinos novas maneiras de ser homem. A propaganda é infeliz porque soa anacrônica, fala de

\section{REFERÊNCIAS}

BOURDIEU, Pierre. A dominação masculina. 6. ed. São Paulo: Bertand Brasil, 2009.

FOUCAULT, Michel. História da sexualidade 1: a vontade de saber. 11. ed. Rio de Janeiro: Edições Graal, 1988.

KATZ, Jonathan Ned. A invenção da heterossexualidade: Rio de Janeiro, Ediouro, 1996.

KAUFMAN, Michael. “Las siete P's de la violencia de los hombres", International Association for Studies of Men, v. 6, n. 2, jun. 1999.

Recebido em: 20 de junho de 2012 Avaliado em: 25 de junho de 2012 Aceito em: 15 de julho de 2012 e para uma mulher que quer fugir do jogo binário, da subordinação e, também, é infeliz porque insinua um interlocutor masculino igualmente ultrapassado.

OLIVEIRA, Pedro Paulo de. A construção social da masculinidade. Belo Horizonte: Editora UFMG, 2004.

RODRIGUES DE LIMA, Fausto. Bündchen também discrimina os homens. Folha de São Paulo, São Paulo, 5 out. 2001.

THÜRLER, Djalma. Masculinidade precária. Contemporâneos. São Paulo: - Revista de Artes e Humanidades, n. 08, 2011. 